\title{
Online and Offline Hybrid Teaching Practice Based on "PAD" Class
}

\author{
Huiwei Chen* \\ Qingdao Huanghai University \\ Qingdao, China \\ 83430761@qq.com
}

\author{
Yuliang Zhang, Fei Feng, Na Liu \\ Qingdao Huanghai University \\ Qingdao, China
}

\begin{abstract}
Under the background of new engineering, there exists some problems in the traditional circuit course teaching, for the purpose of cultivating talents of electrical majors, the research group, advocating independent exploration and cooperative learning, explored online and offline mixed teaching method based on "PAD"(presentation-assimilation-discussion) which emphasized that teachers acted as guiding role while students were principal part in class. In the practice, the research group divided the teaching process into four stages: imparting, internalization, enhancement and consolidation through online and offline combination. In this way, teachers could encourage students to change their passive learning to active learning. The comparison of assessment methods also showed that the teaching effect was satisfactory. This teaching mode makes full use of learning resources, expands the time and space boundary of teaching, and creates a mixed class with cooperation, interaction, innovation and discussion.
\end{abstract}

Keywords-new engineering; circuit; "PAD"; combination of online and offline

\section{INTRODUCTION}

Circuit is the professional basic course of electrical specialty. Through the study of this course, students can master the basic knowledge of circuit theory and receive necessary experimental skill training, so as to prepare for the follow-up professional courses and lay a solid foundation for becoming qualified engineers and technicians in the future. Therefore, whether the students study the circuit course solidly and thoroughly directly affects the study of the follow-up professional courses and the future employment [1]. However, for freshmen who have just come into contact with professional knowledge, circuit is a relatively difficult and boring course, especially in the traditional teaching mode, the phenomenon of "emphasizing theory over practice, emphasizing knowledge over ability" is widespread, which makes students seriously lack the ability to solve problems and practice. Therefore, it is difficult for teachers to teach and students have obvious conflict psychology, which leads to poor classroom atmosphere and teaching effect. In order to improve the quality of teaching, it is necessary to enhance the participation of students in the course of teaching, fully stimulate their interest in learning, synchronously and dynamically grasp the learning situation of students, and gradually explore and form a student-centered teaching mode.

The efficient classroom which is student-centered should be: In the classroom teaching activities, teachers should respect

Qingdao Huanghai University Teaching Team Project of Intelligent Control Technology Course Group (HHJXTD2017005)

Teaching Reform Project of Qingdao Huanghai University: Research on

Hybrid Learning Mode Based on Mobile Internet Environment

(hhxyjg1808) students' subject status, encourage students to think independently and show themselves freely on the basis of understanding and respecting students' individual differences and characteristics, In order to achieve the maximum benefit of classroom teaching, the integration of knowledge and ability, process and method of education and teaching should be realized to the greatest extent and perfect in unit time.

This research is based on the current "new engineering" background, from the perspective of highlighting the comprehensive ability of applied and innovative talents, Based on the actual situation of the electrical specialty in Qingdao Huanghai University, the reform of the teaching method of "student-centered" circuit course is discussed.

\section{Current Teaching Situation of Circuit Course UNDER THE BACKGROUND OF NEW ENGINEERING}

There are 80 class hours in the school circuit course, including 64 class hours for theoretical teaching and 16 class hours for experimental teaching. In recent years, the research group has not only been undertaking the task of classroom teaching and experimental teaching of the circuit course, but also trying to find out how to improve the teaching quality of the course and students' innovation ability in essence. At present, although some results have been achieved, there are still many unsatisfactory points. The problems existing in the teaching process of circuit courses are similar to those existing in other engineering courses [3], There are several points to be improved: first, the traditional teaching method with "teachers speaking and students listening" as the main form still exists, and students' initiative to learn is not high; Second, teachers should teach students according to their aptitude and provide good guidance to students throughout the process.

\section{A. The Influence Of traditional Teaching Methods is Deeply Rooted.}

In the traditional teaching process, the teaching method in which the teacher is the leading role is incomplete. At present, some students still don't realize that they are the main body of the learning process, and their enthusiasm and initiative for learning are not high, so they can't actively participate in the teaching activities. In addition, the teaching time in the class is limited, and there is not enough time for interaction between teachers and students, which is still the traditional teaching state of "teachers speak and students listen". The separation between classroom teaching and after-school learning is serious. Most of the time, students are in a passive state of accepting knowledge, with less thinking activities. It is difficult 
to cultivate students' thinking ability and innovation spirit. Students will find theory teaching boring.

\section{B. Students do not have a Good Grasp of Basic Professional Courses.}

In the teaching of circuit theory, there are the following problems from the perspective of curriculum: part of the theoretical knowledge of teaching is relatively abstruse, and students need to have a certain foundation of mathematical theory, such as calculus, Fourier transform and other mathematical knowledge [4]. Due to the limitation of class hours, teachers can only make simple introductions in limited time and cannot explain them systematically, which leads to students' weak mastery and unsatisfactory teaching effect; Part of the teaching content is relatively old. For basic courses, the content has not changed much for many years. Due to the rapid development of social economy, the development of circuit theory is also very rapid. Some theoretical knowledge and experimental equipment are not updated in time. It is necessary to introduce the latest research results to students in the teaching process and cultivate their innovative spirit. One of the characteristics of the circuit is that it has many concepts, such as components, reference direction, equivalent transformation, input resistance and other parameters. In the process of teaching, teachers should deliberately emphasize the use of basic concepts to promote students to establish a deep understanding of them [5]. If students do not have a solid grasp of knowledge, it is bound to increase the learning difficulty of subsequent courses.

\section{Methods ANd PRActice OF CURRICUlum TEACHING REFORM}

\section{A. Online and Offline Mixed Teaching Preparation Work Based on PAD Class}

Teacher preparation: at the beginning of the semester, this course will be constructed, including the introduction of the course, teachers' team, experimental conditions, course evaluation methods, course syllabus, experimental syllabus, courseware, video, animation, question bank, homework library and other materials. Through the online platform, students can fully understand the main teaching contents, teaching methods, key and difficult contents of each chapter, and define their learning tasks.

Student preparation: the classroom teaching adopts the "group cooperative learning method" to fully mobilize the enthusiasm of students. According to the students' academic basis, interests, personal abilities, gender differences, divide the groups, and match the students with poor performance points. Each group shall appoint a team leader, who shall be fully responsible for organizing the division of labor within the group.

\section{B. Online and Offline Hybrid Teaching Process Based on PAD Class}

Knowledge imparting stage: rough lecture online and offline. In class, the teacher gives a rough introduction to the course content and released targeted online classroom exercises. Teachers' rough lecture does not exhaust the content, leaving students the space to actively study and explore. Through the basic knowledge framework acquired in class, students can understand the key and difficult points, greatly reducing the difficulty of self-study after class. Students participate in group learning with homework, with clear learning objectives, and good learning spur on poor learning. Classroom exercises belong to simple types, and the answers can be found in textbooks or through simple calculations. The purpose is to check students' self-study.

Knowledge internalization stage: study in groups off-line at the end of class. After class, the group leader takes the lead to study and finish the homework through online video and PPT with the group as the unit using fragmented time. Through the background data record of the online platform, the teacher can determine whether the students complete the learning before the specified time node, can understand the completion of homework, timely remind the groups who lag behind in learning, ensure that the self-study before the intensive lecture is implemented in place, and as part of the course assessment. Through the implementation of this stage, students can also gradually develop the habit of independent learning, and can complete the learning within the specified time.

Knowledge enhancement Stage: intensive lecture online in class. The teacher understands the students' self-study through the homework, explains the key points and difficult points purposefully according to the common problems fed back by the homework in the teaching process. Students bring basic knowledge and problems of self-study into the classroom, making offline learning more purposeful, thus fully ensuring the quality of classroom teaching. In this stage, after the learning of online basic knowledge, the off-line teacher's search for defects and key breakthroughs, the rest is to organize students to consolidate and flexibly apply the basic knowledge learned online through carefully designed classroom teaching activities.

Knowledge consolidation stage: online knowledge consolidation after class. With the help of the online platform, the interactive function of the platform is fully explored and used, which is carried out in the way of online teacher-student interaction. It not only realizes unified and generalized help for students, but also realizes accurate help for individuation. For a small number of students with relatively weak learning ability who have not fully mastered the knowledge after previous learning, the teacher can give answers to the questions, and encourage and help them to watch the corresponding micro class or relevant resources suitable for their learning many times; for some students with strong learning ability, the platform can be used to provide deep difficulty exercises and postgraduate entrance examination questions to meet diversification and personalized needs.

\section{EFFECTIVENESS OF TEACHING PRACTICE}

Based on the teaching reform project of Qingdao Huanghai University, the circuit course explores the reform of "student-centered" teaching contents and teaching methods. After the practice of nearly 300 students in 9 classes of 3 sessions, good results have been achieved. It is very common for students to actively contact teachers to consult questions and discuss problems with teacher. It is obvious that students' 
requirements of the development of the times. In the future, the big data of students' learning process can be fully mined and applied based on the network platform, including the development and application of the adaptive learning system, which can detect students' learning process, predict students' test scores, comprehensively evaluate learning quality, and personalize learning environment and content.

\section{REFERENCES}

[1] Jiao Shang, Jie Yan, Zhaofang Zhang. Reflections on "Circuit Theory" Teaching in Independent Colleges [J]. Natural Science, No.6, 2016, Total No.406, 101-102. (In Chinese).

[2] Ying Xiao. On the Strategy of Efficient Classroom Construction Centered on Student Development [J]. Science, Education and Culture Exchange (Zhongxun Journal), 2019(09):110-111.(In Chinese).

[3] Tao Liu. Exploration on the Reform of "Student-centered" Teaching Method for Sensor and Detection Technology Course [J]. Heilongjiang Science, 2019, 10(17):14-17. (In Chinese).

[4] Shanshan Li, Yungui Deng, Yujun Song. Research and Practice on Inquiry Teaching of Circuit Principle Course under the Background of New Engineering [J]. Educational Modernization. August 2019, No.67. 141-143. (In Chinese).

[5] Xiyou Chen, Guanlin Li, Huiwei Zhou. Some Teaching Practices on the Course of "Circuit Theory [J]. Nanjing: Journal of Electrical and Electronic Teaching, 2014, 36 (2): 1-4. (In Chinese).

[6] Ximing Ding. Circuit Course Construction and Teaching Reform under the Background of Applied Undergraduate Talents Cultivation. Electronic World. 2019 No.16.78-79. (In Chinese). 